\title{
Sobre a Estética de Okashi na Tradução de 0 Livro-Travesseiro de Sei Shônagon
}

\author{
Madalena Natsuko Hashimoto Cordaro
}

\begin{abstract}
Resumo: O presente trabalho visa a discutir a conceituação estética de okashi, termo-chave na história da literatura japonesa, em referência particularmente ao período Heian (794-1192), na obra Makura-no Sôshi (O Livro-Travesseiro) da dama da corte Sei Shônagon. Trabalho coletivo do Centro de Estudos Japoneses da USP, as discussões aqui desenvolvidas são frutos de encontros semanais, com uma redação resultante de pesquisa e reflexão individuais da autora, mas com anuência dos tradutores envolvidos.
\end{abstract}

Palavras-chave: literatura japonesa, período Heian ou Média Antigüidade, O Livro-Travesseiro, Sei Shônagon, conceituação estética de okashi.

A área de Literatura Japonesa desenvolve dois projetos: Panorama da Literatura Japonesa e Tradução de Clássicos da Literatura Japonesa. O primeiro encontra-se em andamento, e visa a delinear um amplo painel da história da literatura japonesa que abranja seus vários períodos e que inclua autores e obras principais, sendo seus colaboradores os professores da Área e um número de alunos de pós-graduação e graduação. O segundo projeto, também em andamento, consiste na tradução da obra Makura-no Sôshi 枕草子 (O LivroTravesseiro), da dama da corte Sei Shônagon 清少納言 e conta com a participação das professoras Geny Wakisaka (aposentada), Junko Ota, Luiza Nana Yoshida e Madalena Natsuko Hashimoto Cordaro, tendo tido no início a colaboração de Neide Hissae Nagae, docente da UNESP, campus de Assis. O processo de tradução conjunta experimentou várias fases, tendo, no momento, atingido um modelo funcional. Dado um conjunto de dificuldades de tradução, visto a especificidade cultural do período em que a obra se insere, houve 
necessidade, em primeiro lugar, de criarmos um "vocabulário particular", uma espécie de "dicionário especializado", que nos tem auxiliado em nossa tarefa, composto de verbetes sobre cargos sociais, vestuário, arquitetura, festividades e usos-e-costumes, cores, topografia poética, pássaros, flores, além de um repertório literário alusivo de grande ressonância imagética.

O presente trabalho centrar-se-á num dos verbetes de nosso "dicionário particular", o termo okashi, pois é deveras ampla a sua abrangência semântica. Mas, inicialmente, elucidemos brevemente a obra e sua autora.

Sei Shônagon, nome que the foi dado quando servia na corte, teria nascido por volta do ano 966, sendo seu pai Kiyohara-no Motosuke (908-990), poeta notório e um dos compiladores da coletânea de poesia waka intitulada Gosen Wakash $\hat{u}$. Era também, por causa de seu progenitor, conhecida em vida como Motosuke-no Musume ("filha de Motosuke"). Pesquisas mais recentes levantam até uma implausível hipótese de seu nome ter sido Nagiko, já que nomes próprios somente se tornam comuns muito mais tarde. Nascida, pois, em família de poetas - seu irmão Kaishû é poeta e monge-chefe ligado ao ex-imperador abdicado Kazan-in - a autora, entretanto, embora profunda conhecedora da poesia japonesa, dela abdica para compor em prosa, ainda que de grande sabor poético. Assim, embora a obra Mumyô-zôshi (O Livro Sem Título $)^{1}$, de inícios do período Kamakura, refira a "filha de Kiyohara-no Motosuke" como grande poeta, a coletânea Goshûi Wakash $\hat{u}$, de 1086, registra somente dois poemas seus. Após separar-se de seu suposto marido, Tachibana Norimitsu, a quem teria desposado no ano 983, poeta também afiliado a Kazan-in, Sei Shônagon entra a serviço da corte de Teishi (ou Sadako, leitura japonesa), consorte do imperador Ichijô, em 993, e torna-se a porta-voz das tendências estéticas de sua corte, havendo até estudiosos que atribuem à consorte imperial uma co-autoria da obra em questão, tal sua importância nos ditames do gosto elegante. Consta que ambas possuíam formação em Estudos Chineses. No ano de 995, o kanpaku Michitaka, pai de Teishi, retira-se da corte, o que gera instabilidade em sua família e, quando seu filho Korechika não consegue sucedê-lo no cargo (que acaba por ser ocupado pelo irmão mais novo de seu pai, Michinaga), Teishi deve

\footnotetext{
${ }^{1}$ Obra semi-ficcional e de crítica, talvez escrito por uma mulher ligada a Fujiwara Teika e Fujiwara Takanobu, entre os anos 1196 e 1202, na qual se discute as narrativas monogatari de modo extensivo e exaustivo, que conclui com uma discussão sobre as grandes escritoras do período Heian: Ono-no Komachi, Sei Shônagon, Izumi Shikibu, Murasaki Shikibu e outras. In Classical Japanese Literature, pp.201-2.
} 
deixar o palácio imperial e mudar-se para Konijô-in, residência de sua família, Fujiwara. É depois transferida pelo imperador (que toma Shôshi, filha de Michinaga, como consorte imperial) para Shiki-no Mizôshi, próximo ao palácio imperial, sendo acompanhada por Sei Shônagon, que se compadece de seu infortúnio. Os anos de 997 a 1000, assim, são de um estilo de vida frugal embora ainda elegante, apesar das dificuldades políticas enfrentadas. Supõe-se que Sei Shônagon escrevesse sua obra, durante esse período, para alegrar a ex-consorte imperial Teishi e, após a morte desta no ano 1000, de parto, para glorificar-lhe a memória. Assim, embora já fisicamente não existisse uma corte que envolvesse a amada consorte imperial para quem ler seus escritos, Sei Shônagon teria continuado a escrever para ela, uma leitora imaginária, e sob seu ponto de vista aristocrático e refinado. Sabe-se pouco sobre sua vida posterior, se teria tomado votos budistas ou se teria tornado a casar, desta feita com Fujiwara Muneyo. De qualquer forma, é certo que deixa a corte e passa a morar na província de Settsu.

Ainda que não se precise exatamente em que circunstâncias $O$ LivroTravesseiro foi escrito, segundo a teoria mais aceita, teria havido uma primeira versão em 995-6, uma segunda por volta do ano 997-8 e novas adições até, pelo menos o ano 1021 - algumas fontes trazem o ano 1017. Composto de trechos de extensão variada, pode-se classificar seus temas em três grupos: 1. listas de itens classificados que agrupam e comparam coisas semelhantes, 2. trechos narrativos como se fossem parte de diário sobre as atividades diárias no palácio imperial e 3. juízos sobre elementos naturais e sociais e reflexões sobre a vida.

O primeiro grupo temático inclui tropos poéticos (utamakura), usos-ecostumes e vestuário e festividades da corte, das artes e dos entretenimentos, além de um rol de elementos naturais, listando não apenas os espécimes mais apreciados, mas também os mais difíceis de imaginar, sendo a seleção uma característica bem particular de Sei Shônagon. Não se trata, assim, de uma mera listagem de coisas, mas de uma tentativa de conceituação das "coisas-melhores" também nas categorias de pessoas, cargos, vistas paisagísticas, atividades, atos e gestos, havendo até elaborações como uma lista de "Coisas que parecem pretensiosas quando escritas em ideogramas".

O segundo trata de narrativas de um dia e um lugar particular, grande parte deles relacionadas ao tempo em que servia no palácio à consorte imperial Teishi, como uma excursão a algum templo famoso, uma animada festa no palácio, um evento relacionado a algum nobre, uma relação amorosa, as atividades imperiais. 
O terceiro grupo, de juízos, ou julgamento segundo um olhar estético da elegância cortesã, mostra muita liberdade associativa, não raro mesclando listas, o que torna tênue o limite entre os dois grupos temáticos.

Existem manuscritos de duas linhas: a linha Ruisanbon tentou organizar os trechos de acordo com os três grupos anteriormente citados e se subdivide nos manuscritos Sakaibon, cuja cópia é de 1570, e Maedabon, a mais antiga cópia da obra, de meados do século XIII; a linha Zassanbon não se restringe a tal método e se subdivide nos manuscritos Nôinbon, cuja cópia mais antiga é do séc. XVII, e sankanbon, de 1475. Há muitas variantes textuais nas diferentes cópias remanescentes, mas a maior parte dos especialistas acredita que originariamente a obra devesse mesclar os três grupos de trechos. Nossa equipe de tradutores elegeu a versão comentada e anotada por Watanabe Minoru (1991), que já foi professor visitante junto a nosso Programa de Pós-Graduação em 1998, mas também consultou a de Hagitani Boku (1978), além de sempre cotejar as traduções para o inglês de Ivan Morris (1991) e para o francês de André Beaujard (1966).

Na literatura japonesa, vê-se, segundo estudo de Hisamatsu Sen'ichi (1963) ${ }^{2}$, um número de conceitos estéticos particulares a determinados períodos históricos, que pode ser ilustrado na seguinte tabela:

\footnotetext{
${ }^{2}$ In The Vocabulary of Japanese Literary Aesthetics, p.9. A presente tabela foi adaptada em termos de datação de períodos, tendo-se preferido seguir a nomenclatura mais corrente na delimitação histórica geral, a qual toma por princípio as cidades nas quais se concentrava o poder político, e tendo-se considerado a época contemporânea. Hisamatsu considera o período moderno somente até o fim da era Meiji, 1912, enquanto englobamos aqui como data-marco a II Guerra Mundial. Dada a especificidade e complexidade dos termos estéticos aqui arrolados, optou-se por não tentar traduzilos.
} 


\begin{tabular}{|l|l|l|l|}
\hline PERÍODO Ou & HUMOR & SUBLIMIDADE & ELEGÂNCIA \\
\hline $\begin{array}{l}\text { Antigüidade } \\
\text { Yamato ( séc.VIII) 大 } \\
\text { 和時代 }\end{array}$ & $\begin{array}{l}\text { Mei } \\
\text { 直 }\end{array}$ & $\begin{array}{l}\text { Sei } \\
\text { 清 }\end{array}$ \\
\hline $\begin{array}{l}\text { Média Antigüidade ou } \\
\text { Heian (794-1192) } \\
\text { 平安時代 }\end{array}$ & $\begin{array}{l}\text { Okashi } \\
\text { をかし }\end{array}$ & $\begin{array}{l}\text { Taketakashi } \\
\text { たけ高し }\end{array}$ & $\begin{array}{l}\text { Aware } \\
\text { 哀 }\end{array}$ \\
\hline $\begin{array}{l}\text { Medieval ou } \\
\text { Kamakura-Muromachi } \\
\text { (1192-1600) } \\
\text { 鎌倉室町時代 }\end{array}$ & $\begin{array}{l}\text { Mushin } \\
\text { 無心 }\end{array}$ & $\begin{array}{l}\text { Yûgen } \\
\text { 幽玄 }\end{array}$ & $\begin{array}{l}\text { Ushin } \\
\text { 有心 }\end{array}$ \\
$\begin{array}{l}\text { Pré-moderno ou Edo } \\
\text { (1600-1868) } \\
\text { 江戸時代 }\end{array}$ & $\begin{array}{l}\text { Kokkei } \\
\text { 滑稽 }\end{array}$ & $\begin{array}{l}\text { Sabi, Karumi } \\
\text { さび、軽み }\end{array}$ & $\begin{array}{l}\text { Sui, Tsû, Iki } \\
\text { 粋、通、いき }\end{array}$ \\
\hline $\begin{array}{l}\text { Moderno ou Meiji, } \\
\text { Taishô e parte de } \\
\text { Shôwa (1868-1945) } \\
\text { 明治、大正、昭和 }\end{array}$ & $\begin{array}{l}\text { Koten } \\
\text { 古典 }\end{array}$ & $\begin{array}{l}\text { Shajitsu } \\
\text { 写実 }\end{array}$ & $\begin{array}{l}\text { Rôman } \\
\text { 浪漫 }\end{array}$ \\
\hline
\end{tabular}

Vê-se, assim, que o termo okashi é central na conceituação estética que se liga ao humor e que se desenvolve, em linhagem direta, até a modernidade, como também o fazem os outros termos-chave de sublimidade e elegância. Atenta Hisamatsu Sen'ichi, secundado por Tanaka Michimaro, que a palavra okashi não é encontrada na Antigüidade e que, no período Heian, é utilizado em dois sentidos: para indicar um sorriso ou um chiste ou para sugerir algo que, embora alegre, de percepção perspicaz e engenhosa, encontrava-se ainda muito próxima à elegância. Atenta Hisamatsu, ainda, que o grande estudioso Motoori Norinaga, afiliado ao movimento Kokugaku, Estudos Vernaculares, considerou a primeira acepção como derivação de uso popular dos homens comuns, no termo oko 愚 (tolo, engraçado) e a segunda como derivação de uso entre os nobres elegantes, no termo omukashi 面し, 向し (alegre, satisfeito, que sente sensação agradável). Em ambos os casos, a qualidade estética de alegria e brilho se iguala, mas o

\footnotetext{
${ }^{3}$ Embora Hisamatsu, in op.cit. na nota anterior, não tenha incluído este conceito, inclui-o em outra obra em que consta como organizador, Nihon Bungaku-shi (História da Literatura Japonesa).
} 
desenvolvimento do primeiro geraria incongruência, comicidade e impropriedade e, do segundo, harmonia, apreciação rápida, engenhosidade e elegância.

Em O Livro-Travesseiro, o termo aparece 466 vezes, e o sentido se encontra normalmente associado a uma variante de beleza clara, alegre, discreta, sutil e elegante. Analisemos o primeiro trecho, cuja tradução se transcreve a seguir por completo, visando proporcionar um contexto mais amplo:

Na primavera, o amanhecer. É quando, palmo a palmo vão se definindo as esmaecidas linhas das montanhas e no céu arroxeado tremulam delicadas nuvens.

No verão, a noite. Em especial, os tempos de luar, mas também as trevas, de vaga-lumes entrecruzando-se em profusão. Ou, então, aqueles solitários ou mesmo em pares seguindo com brilhos fugazes. A chuva também é bela.

No outono, o entardecer. São os momentos do arrebol da tarde em que o sol se acha prestes a tocar as colinas, quando se tornam comoventes, mesmo os três, quatro ou dois corvos que se apressam para os ninhos, e o que diríamos então, ao avistarmos as minúsculas aves migrantes seguindo em filas, que encantadoras! O sol já posto, melancólicos ficam o ciciar do vento e o canto dos insetos.

No inverno, o despertar. Indescritível é, com a neve caindo, e nele incluo a brancura cega da geada. Mesmo na ausência dela, em manhãs de um frio cortante, o apressar das pessoas em acender o fogo e o corre-corre entre os aposentos com os carvões acesos são cenas típicas da estação. O sol já nas alturas e o frio mais ameno, não nos cativa mais a chama coberta de cinzas do braseiro.

O trecho estabelece os melhores momentos de cada estação e as atividades humanas mais características, relacionando-lhes pássaros e insetos. O termo okashi aparece duas vezes: 


\begin{abstract}
夏はよる。月のころはさら也、闇もなを、ほたる の多くとびちがひたる。(...) 雨などふるも、をかし。

Natsuwa yoru. Tsukino korowa saranari, yamimo nao hotaruno ôku tobichigaitaru. (...). Amenado furumo
\end{abstract} okashi. - trecho 1, página 3, linhas 3 4.

[No verão, a noite. Em especial, os tempos de luar, mas também as trevas, de vagalumes entrecruzando-se em profusão (...). A chuva também é bela.]

Verifiquemos a tradução de Morris: “(..), and even when it rains, how beautiful it is!" (p.21). Embora mais emotiva, também o termo escolhido é o mesmo. Já na tradução de Beaujard, "Même s'il pleut, la nuit d'été me charme" (p.25), ocorre uma idéia de concessão à chuva, que mesmo assim, "encanta", também um termo análogo. Em nossas discussões, notamos que muitas vezes as traduções com as quais comparamos o texto original se impregnam de um tom por demais emotivo, e quase sempre explicativo, com grandes acréscimos de interpretação, devido às especificidades culturais já aqui aludidas. Nossa opção foi sempre no sentido de manter o caráter sintético original, que, muitas vezes, leva a ambigüidades - mas, para que exauri-las?

A seguir analisaremos mais alguns exemplos, sempre comparando com as traduções que nos foram acessíveis:

まいて、雁などのつらねたるが、いとちいさくみ ゆるは、いとをかし。

Maite karinadono tsuranetaruga, ito chiisaku miyuruwa, ito okashi. - trecho 1, pág.3, lin.6-7.

CEJ: [(...), e o que diríamos então, ao avistarmos as minúsculas aves migrantes seguindo em filas, que encantadoras!]

Morris: [(...); more charming still is a file of wild geese, like specks in the distant sky.], p.21.

Beaujard: [Et quand les longues files d'oies sauvages paraissent toutes petites!, c'est encore plus joli.], p.25.

Hisamatsu: [It's still more diverting to see how small a column of wild geese appears.], pp.21-2. 
No trecho 2, que trata das épocas melhores do ano, página 4, linha 2, os vários meses são ichinennagara okashi [いち年ながら、をかし]. Segundo CEJ: [Todos, de acordo com a ocasião, são interessantes.], Morris: [não consta] e Beaujard: [Toute l'année est jolie., p.26]. No trecho 3, ou ainda 2, de acordo com a versão de Watanabe, o Ano Novo é samakotoni okashi [さまことにをか ᄂ], p.2, lin.5. Segundo CEJ: [torna-se gratificante], Morris: [What a pleasure, p.21] e Beaujard: [C'est vraiment ravissant, p.26]. Mais adiante, quanto ao oitavo dia do primeiro mês, hitobito yorokobishite hashirisawagi, kurumano otomo tsuneyoriwa kotoni kikoete okashi [人々悦してはしりさはぎ、車のを とも、つねよりはことに聞てをかし], p.5, lin.6,. Segundo CEJ: [Tornam-se excitantes o reboliço das carruagens dos oficiais da Corte], Morris: [(...) - all very fascinating, p.22] e Beaujard: [(...) c'est bien amusant, p.27]. Notamos que as interpretações começam a se expandir, incluindo "interessante", "gratificantes", "prazeroso", "excitante", "fascinante", chegando até a "sublime". Como termo análogo e muitas vezes utilizado como sinônimo, o mais importante conceito que se relaciona a okashi seria omoshiroshi 面白し (interessante, intrigante, divertido), um termo mais antigo encontrável também já na antigüidade, significando apreciação que enfatiza brilho e alegria, embora às vezes não contenha implicação de humor. De qualquer forma, em oposição ao termo aware 哀 e seus derivados aware-nari e mono-no aware, cuja conotação se impregna de sombra e melancolia, o campo semântico de okashi inclui somente uma beleza de luz.

Foi aludido anteriormente que a primeira acepção, de humor, e a segunda, de elegância, proviriam de uma visão de povo e de corte, respectivamente. Oras, se ambas encontram expressão na obra de Sei Shônagon, talvez pudéssemos aventar que há uma consciência de uma percepção, quanto aos aspectos múltiplos da vida humana e da natureza, que se poderia compreender como sendo dicotômica. Lembremos aqui oposições constantes no pensamento e na produção artística do período Heian: a oposição entre pintura japonesa e chinesa (yamato-e 大和絵, “pintura de Yamato”, ou onna-e 女絵, “pintura-mulher”, e kara-e 唐絵, ”pintura do continente", ou otoko-e 男絵, “pintura-homem”), caligrafia e sistema de escrita japoneses e chineses (onna-de 女手, “mão-mulher”, e otoko-de 男手, "mão-homem"), os quais, embora coexistindo, indicam diferentes gêneros ou técnicas ou formas. Assim, a oposição nobreza-povo não se calcaria num desprezo de uma para com o outro - como alguns críticos afirmaram, indignados 
contra o que supõem ser uma atitude de escárnio perante as classes menores, em oposição a uma adoração irrestrita à família imperial -, embora a primeira, sim, fosse o modelo exemplar de elegância e refinamento e o segundo, de ingenuidade e riso.

Analisamos até aqui variações da segunda acepção, a ligada a okashimi. Quanto à primeira acepção, oko, eivada de humor, analisemos dois exemplos. $\mathrm{O}$ primeiro se insere na comemoração de certas datas do ano, dentre as quais, no décimo quinto dia do primeiro mês, ocorre um jogo de tentar acertar, com gravetos chamuscados, a retaguarda de jovens e damas. É descrita a atitude daqueles que são inadvertidamente atingidos:

いかなる心にかあらん、なきはらだちつつ、うち
つる人をのろひ、まがまがしくいふもあるこそをか
しけれ。
$\quad$ Ikanaru kokoronika aran, naki haradachitsutsu, uchitsuru hitoo noroi, magamagashiku yûmo arukoso okashikere. - trecho 2, p.6, lin.3-4

CEJ: [Quais seriam seus intentos? Há as que se irritam, choram e amaldiçoam; e curioso é saber que algumas até blasfemam.]

Morris: [The strange thing is that, when a woman is hit, she often gets angry and burst into tears; then she will upbraid her assailant and say the most awful things about him - most amusing.], p.23.

Beaujard: [Que pouvent-elles alors penser? Elles pleurent, s'emportent, maudissent ceux qui les ont frappées, en parlent avec aversion. Que c'est amusant!], p.27.

Nota-se que o termo é utilizado numa situação lúdica de um tipo de humor que leva a um riso e comicidade de atitudes que desobedecem às rigorosas regras de etiqueta da corte. Entretanto, não se trata de um riso ligado a minikushi 醜し, "feio, horrível, ridículo" e sim ao "excitante, engraçado, prazeiroso", peculiar de um refinamento de corte. 
No quinto trecho, que trata de uma ocasião em que a imperatriz hospedara-se na residência de Narimasa, secretário sênior do Departamento de Assuntos das Consortes Imperiais, quando o anfitrião tenta se infiltrar no quarto das damas, à noite, abusando de sua condição privilegiada, desenrola-se uma cena descrita como okashi:

$$
\begin{aligned}
& \text { (...) おどろきて見れば、木丁のうしろにたてた } \\
& \text { る灯台の光はあらはなり。障子を五寸ばかりあけて } \\
& \text { いふなりけり。いみじうをかし。さらにかやうのす } \\
& \text { きずきしきわざ、ゆめにせぬものを、わが家におは } \\
& \text { しましたりとて、むげに心にまかするなめり、と思 } \\
& \text { ふもいとをかし。 } \\
& \text { (...) odorokite mireba, kichôno ushironi tatetaru } \\
& \text { tôdaino hikariwa arawanari. Shôjio gosunbakari akete } \\
& \text { yûnarikeri. Imiju okashi. Sarani kôno sukizukishiki waza, } \\
& \text { yumeni senu monoo, wagayani owashimashitaritote, } \\
& \text { mugeni kokoroni makasurunameri, to omoumo ito okashi. }
\end{aligned}
$$
- pág.11, linhas 4 7.

CEJ: [Ao ser despertada por essas palavras, pude ver claramente a luz da lamparina colocada atrás da cortina. Narimasa falava através da porta corrediça entreaberta. Foi muito engraçado. Muito mais engraçado foi pensar que Narimasa, normalmente avesso a conquistas, tenha tomado uma atitude tão ousada, levado pelo fato de encontrar-se em sua própria casa.]

Morris: [I looked up in amazement, and by the light of the lamp that had been placed behind the curtain of state I could see that Narimasa was standing outside the door, which he had now opened about half a foot. The situation amused me. As a rule he would not have dreamt of indulging in such lecherous behaviour; (...)], trecho 7 , p.28.

Beaujard: [Comme je m'éveillais et regardais, surprise, la lumière d'une lampe placée derrière l'écran me le fit voir distinctement. Il parlait en ouvrant la porte 
d'environ cinq pouces. Cétait fort drôle. J'avais aussi beaucoup de plaisir à penser qu'à l'ordinaire, cet homme n'aurait probablement jamais fait, même en revê, une chose aussi déraisonnable.], trecho 4, p.31.

A presente descrição de jogo de aproximação e sedução das damas da corte provoca uma atitude jocosa para com os meandros da corte amorosa, desnudando de modo perspicaz o comportamento de um homem que toma liberdades impensadas e inapropriadas por se encontrar em terreno próprio.

Debruçando-nos sobre o verbete okashi em dicionário especializado em língua clássica, encontramos as seguintes acepções: 1. convidativo à apreciação; 2. interessante, notório; 3. atraente por sua beleza; 4. gracioso, mimoso; 5. esplêndido, magnífico; 6. de tão interessante, faz rir e 7. risível, diferente, raro, incomum. Até o momento, registramos as seguintes possibilidades: belo, bonito, mimoso, atraente, charmoso, encantador, gratificante, excitante, intrigante, impressionante, admirável, elegante, refinado, sublime, magnífico, maravilhoso, interessante, divertido, engraçado. Até o fim de nossa empreitada, quiçá se enriquecerá ainda mais a presente lista. Não se conclua, entretanto, que se trate de uma falta de vocabulário por parte da dama de corte Sei Shônagon: antes, assim se configura sua escritura concisa, de expressão sintética e multisignificante. A nós somente nos cabe empobrecê-la através de uma variedade de sentidos limitados.

\section{BIBLIOGRAFIA}

AKIYAMA \& YAMANAKA. Nihon Bungaku-no Rekishi (História da Literatura Japonesa), vol.3. Tokyo, Kadokawa, 1968.

BEAUJARD André, trad. Sei Shônagon - Notes de Chevet. Paris, Gallimard, 1966.

HAGITANI Boku, org. Makura-no Sôshi (O Livro-Travesseiro). Tokyo, Shinchôsha, 1978.

HISAMATSU Sen'ichi. The Vocabulary of Japanese Literary Aesthetics. Tokyo, Centre for East Asian Cultural Studies, 1963. 

, org. "Kodai Bungaku-ni Okeru Bi-no Ruikei” ("Tipologia Estética na Literatura Clássica”). In Nihon Bungaku-shi (História da Literatura Japonesa). Tokyo, Chôbundô, 1983 (1ª.ed.: 1965).

ISHIDA Jôji, org. Nihon Koten Bungaku - Makura-no Sôshi (Literatura Clássica Japonesa - O Livro-Travesseiro), vol.8. Tokyo, Kadokawa, 1976.

KIMURA Tadanaka, org. Kagerô Nikki / Makura-no Sôshi (vol.6 da coleção Nihon-no Koten - Obras Clássicas Japonesas).Tokyo, Shûeisha, 1979.

MINER Earl, ODAGIRI Hiroko e MORRELL Robert E. The Princeton Companion to Classical Japanese Literature. Nova Jersey, Princeton University Press, 1988 (1 $1^{\mathrm{a}}$.ed.:1985).

MORRIS Ivan, trad. The Pillow Book of Sei Shônagon. Nova York, Columbia University Press, 1991.

WATANABE Minoru, org. Makura-no Sôshi (O Livro-Travesseiro). Tokyo, Iwanami, 1993 (1 $1^{\text {a }}$ ed.: 1991).

Dicionário especializado em língua clássica Iwanami Kogo Jiten, compilado por ÔNO Susumu, SADAKE Akihiro e MAEDA Kingorô. Tokyo, Iwanami, 1980 (1ª .ed.: 1974).

Abstract: The present work aims to discuss the aesthetic concept of okashi, key term in Japanese literature history, particularly in reference to Heian period (794-1192), in Makura-no Sôshi (The Pillow Book) written by court lady Sei Shônagon. Collaborative work joining professors affiliated to the Center for Japanese Studies of University of São Paulo, the discussions here shown are the results of weekly meetings. The present essay is a result of the author's own individual study and research, but with the other translators consent.

Key-words: Japanese literature, Heian period or Medium Antiquity, The Pillow Book, Sei Shônagon, aesthetic concept of okashi. 